\title{
Pemberdayaan Masyarakat di Kawasan Cagar Budaya ${ }^{1}$
}

\author{
Destha T Raharjana ${ }^{2}$, Pande Made Kutanegara ${ }^{3}$ \\ Universitas Gadjah Mada \\ email: desthapuspar@ugm.ac.id
}

\begin{abstract}
Abstrak
Keberadaan cagar budaya di suatu daerah perlu melibatkan masyarakat setempat dalam pemanfaatannya. Masyarakat di sekitar cagar budaya ditempatkan sebagai subjek dan menjadi bagian dari kegiatan konservasi dan pemanfaatan. Mandat UU No. Warisan Budaya 11/2010, juga menempatkan masyarakat sebagai agen penting pelestarian, keamanan, perlindungan dan pemeliharaan pelestarian budaya. Artikel ini mengulas potensi dengan berfokus pada pengembangan program pemberdayaan masyarakat. Studi lokus di desa Seloharjo, Kecamatan Pundong, Kabupaten Bantul, Yogyakarta. Desa ini memiliki warisan budaya berupa Goa Jepang, Goa Surocolo, dan Sendang (musim semi) yang juga bernama Sendang Surocolo. Melalui pendekatan partisipatif, penambangan data dilakukan dengan observasi, wawancara mendalam dan diskusi bersama yang melibatkan tokoh masyarakat untuk membahas peluang untuk kebutuhan dan program pemberdayaan. Pusat Studi Pariwisata UGM, Pusat Pelestarian Warisan Budaya DIY (BPCB), dan masyarakat setempat melakukan proses ini bersama. Hasilnya, berhasil memetakan potensi, berhasil merumuskan program bagi masyarakat sekitar untuk dapat memperoleh manfaat dari keberadaan pelestarian budaya. Keberadaan gua Jepang, mata air Surocolo dan didukung oleh pemandangan yang mengarah ke pantai Selatan dapat menarik wisatawan. Ekonomi "baru" dalam bentuk pariwisata telah dibentuk dan dijalankan oleh Kelompok Kesadaran Pariwisata setempat. Program pemberdayaan yang dihasilkan melibatkan multi pemangku kepentingan, dalam pemberdayaan masyarakat di bidang pariwisata, ekonomi kreatif, seni budaya dan pengembangan kapasitas di bidang kewirausahaan.
\end{abstract}

Kata kunci: area warisan budaya, pemberdayaan, program pemberdayaan masyarakat, goa jepang, surocolo

\begin{abstract}
The existence of cultural heritage in an area needs to involve the local community in its utilization. Communities around cultural reserves are placed as subjects and become part of conservation and utilization activities. Mandate of Law No. Cultural Heritage 11/2010, also places the community as an important agent of preservation, security, protection and maintenance of cultural preservation. This article reviews potential by focusing on the development of community empowerment programs. Locus study in Seloharjo village, Pundong sub-district, Bantul Regency, Yogyakarta. This village has cultural heritage in the form of Goa Japan, Goa Surocolo, and Sendang (spring) which is also named Sendang Surocolo. Through a participatory approach, data mining is carried out by
\end{abstract}

\footnotetext{
a Artikel ini diolah dari hasil studi "Potensi Pemberdayaan Masyarakat Pundong Bantul Yogyakarta", hasil kerjasama Balai Pelestarian Cagar

Budaya (BPCB) DIY dan Pusat Studi Pariwisata UGM, tahun 2017.

${ }^{1}$ Staf peneliti di Pusat Studi Pariwisata UGM, selaku anggota tim studi.

${ }^{2}$ Ketua tim studi, dosen di Departemen Antropologi FIB-UGM Yogyakarta.
} 
Destha T. Raharjana', Made Pande Kutanegara ${ }^{2}$-Pemberdayaan Masyarakat di Kawasan Cagar Budaya...

observation, in-depth interviews and collated discussions involving community leaders to discuss opportunities for needs and empowerment programs. Centre for Tourism Studies UGM, DIY Cultural Heritage Conservation Center (BPCB), and the local community carried out this process together. The result, succeeded in mapping potential, succeeded in formulating a program for the surrounding community to be able to benefit from the existence of cultural preservation. The existence of Japanese caves, Surocolo spring and supported by landscapes leading to the South coast can attract tourists. A "new" economy in the form of tourism has been formed and run by the local Tourism Awareness Group. The empowerment program produced involves multi stakeholders, in community empowerment in the fields of tourism, creative economy, cultural arts and capacity building in the field of entrepreneurship.

Keywords: cultural heritage area, empowerment, community empowerment program, goa japan, surocolo

\section{PENDAHULUAN}

Upaya melibatkan masyarakat dalam kerangka pemanfaatan cagar budaya menjadi fokus dalam kajian ini. Penelitian partisipatif ini dijalankan bersama masyarakat desa Seloharjo yang memiliki situs Goa Jepang. Masa pendudukan tentara Jepang di tanah air banyak bala tentaranya memanfaatkan goa-goa, baik goa alami maupun goa buatan yang dibuat dengan mengerahkan tenaga kerja pribumi. Goa tersebut dibuat untuk pertahanan, persembunyiaan, perlindungan, dan penyimpanan senjata masa Perang Dunia II.

Kajian ini mengambil setting Goa Jepang tidak jauh dari Pantai Parangtritis. Lokasinya di bukit Pundong, Desa Seloharjo, Kecamatan Pundong, Bantul. Goa Jepang ini dibangun tahun 1942-1945 untuk tempat pengintaian dan pertahanan. Saat ini Goa Jepang tengah berkembang menjadi destinasi "alternatif". Cukup banyak wisatawan yang datang karena tertarik keindahan alam pantai selatan Jawa. Hanya saja, sebagai destinasi wisata baru, fasilitas yang ada di tempat tersebut masih sangat terbatas. Sebagai contoh adalah belum tersedia fasilitas penunjang. Akses jalan menuju lokasi situs juga masih minim. Meskipun jalan sudah diaspal namun jalan yang sempit menyulitkan wisatawan berkunjung ke goa terutama bila mempergunakan mobil. Jalan menanjak dengan tikungan yang berkelok curam sehingga memerlukan kehati-hatian pengendara kendaraan. 


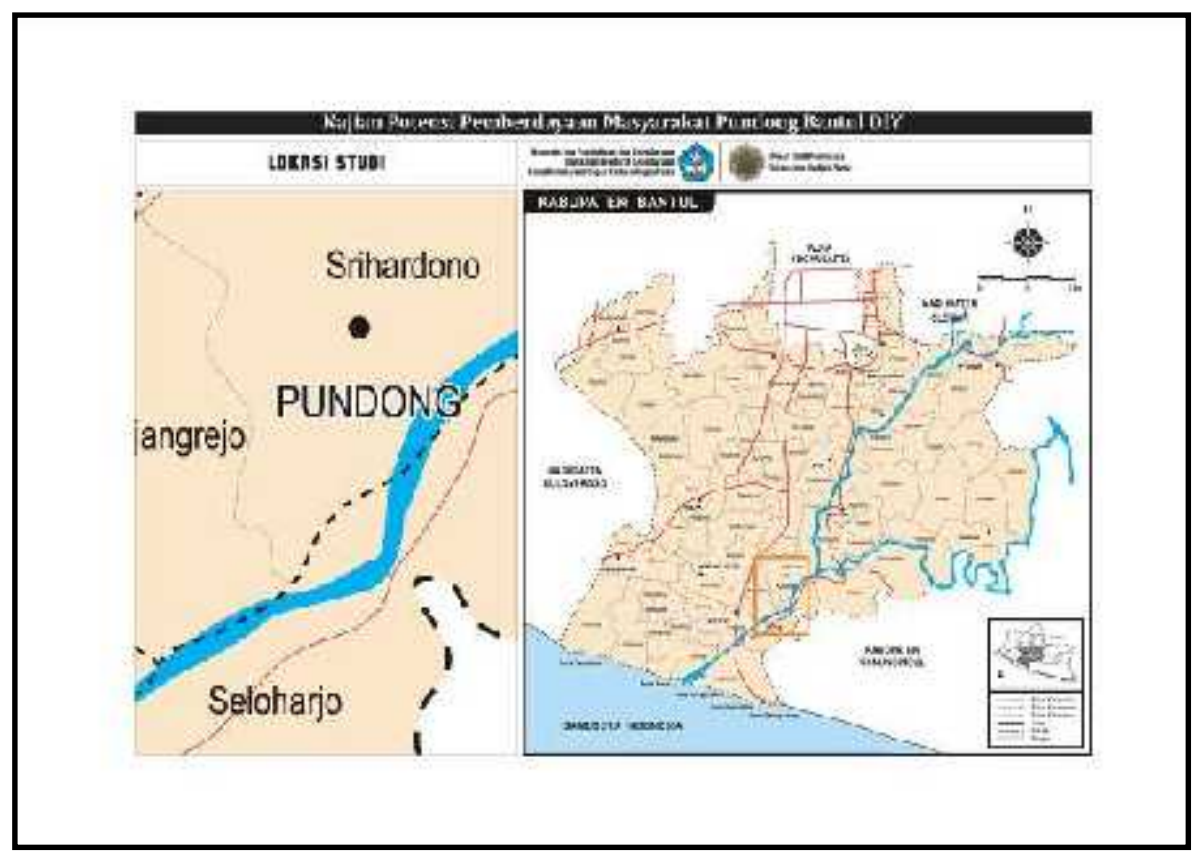

Gambar 1. Lokasi Kajian

Selain Goa Jepang, di lokasi ini terdapat pula Goa Surocolo. Situs goa ini pernah dipergunakan Sunan Amangkurat Mas bersembunyi saat melawan Belanda. Pada situs ini terdapat dua buah sendang yang diberi nama Sendang Surocolo. Lokasi sendang berada di Dusun Ngreco, Desa Seloharjo, Kecamatan Pundong. Tidak jauh dari sendang terdapat pohon Randu Alas diperkirakan usianya sudah lebih dari 350 tahun. Selain itu terdapat pohon Kepoh yang usianya tidak kurang dari 250 tahun. Lokasi ini dipercaya memiliki kekuatan gaib, sehingga sering dipergunakan untuk bertapa oleh beberapa orang yang berasal dari luar daerah.

Upaya pemanfaatan situs Surocolo sebagai bentuk pelestarian sudah dilakukan. Salah satu bentuk pemanfaatan adalah perayaan event merti dusun. Merti bumi atau merti dusun adalah semacam tradisi memule (memelihara/ merawat/ menjaga) leluhur. Mule segala hal yang ada di atas dan di dalam bumi, memule langit seisinya, memule tanah pekarangan masing-masing, memule tanah miliknya masing-masing. Kegiatan budaya yang dilakukan di Surocolo untuk memule hal-hal tersebut juga ditujukan untuk semakin menghidupi Surocolo sebagai destinasi wisata budaya. Guna mendayagunakan potensi, kajian menfokuskan kepada perancangan program pemberdayaan masyarakat. Tujuannya, untuk memetakan kebutuhan pemberdayaan masyarakat sesuai dengan ketersediaan sumber daya sebagai upaya mendukung peningkatan kesejahteraan masyarakat dan kualitas destinasi wisata. Sekaligus dihasilkan agenda aksi pemberdayaan masyarakat yang berorientasi pada pengembangan destinasi wisata dan pelestarian cagar budaya.

\section{Tinjauan Pustaka}

Dalam mengkaji pemberdayaan, Sumodinigrat (1997) menjelaskan pemberdayaan sebagai kemampuan invididu yang bersenyawa dengan masyarakat dalam membangun 
keberdayaan. Pemberdayaan sebagai upaya untuk meningkatkan harkat dan martabat lapisan masyarakat yang dalam kondisi sekarang tidak mampu melepaskan diri dari perangkap kemiskinan. World Bank (2011) menunjuk pemberdayaan sebagai upaya untuk memberikan kesempatan dan kemampuan kepada kelompok miskin agar mampu, berani menyuarakan pendapat/ide, atau gagasan-gagasannya serta kemampuan dan keberanian memilih sesuatu yang terbaik bagi pribadi, keluarga, dan masyarakatnya. Pendeknya, pemberdayaan tidak lain sebuah proses guna meningkatkan kemampuan dan sikap kemandirian. Kelsey dan Hearne (1955) menyatakan falsafah pemberdayaan,"helping people to help them-selves", bekerja bersama masyarakat untuk membantunya agar mereka dapat meningkatkan harkatnya sebagai manusia.

Upaya pemberdayaan dapat dilihat dari tiga sisi; pertama, menciptakan suasana/iklim yang memungkinkan potensi masyarakat berkembang. Di tahap ini berdasarkan atas pengenalan bahwa setiap manusia memiliki potensi. Hal ini memiliki arti bahwa, sama sekali tidak ada masyarakat yang sama sekali tanpa daya. Sehingga adanya pemberdayaan, masyarakat tersebut dimotivasi kesadaran potensi yang dimiliki serta berupaya untuk mengembangkannya. Kedua, pemberdayaan berfungsi untuk memperkuat potensi yang dimiliki masyarakat. Ketiga, memberdayakan mengadung pula arti melindungi. Dalam proses pemberdayaan harus dicegah yang lemah menjadi tambah lemah. Kondisi ini memberikan makna bila sejatinya pemberdayaan bukan membuat masyarakat menjadi tergantung pada segala bentuk program charity. Pendekatan utama dari pemberdayaan adalah masyarakat tidak dijadikan objek namun sebagai subjek dari proses pembangunan itu sendiri. Dalam pengertian lebih luas pemberdayaan masyarakat merupakan proses untuk menfasilitasi dan mendorong masyarakat agar mampu menempatkan diri secara proposional dan menjadi pelaku utama dalam memanfaatkan lingkungan strategisnya untuk mencapai suatu keberlanjutan. Lewat program pemberdayaan tidak lain warga setempat didorong untuk memiliki kemampuan dalam memanfaatkan sumber daya yang dimilikinya serta terlibat penuh dalam mekanisme produksi, ekonomi, sosial dan ekologi. Wilson (dalam Sumaryadi, 2004) menjelaskan bahwa kegiatan pemberdayaan merupakan suatu siklus kegiatan yang terdiri, seperti tampak pada gambar berikut. 


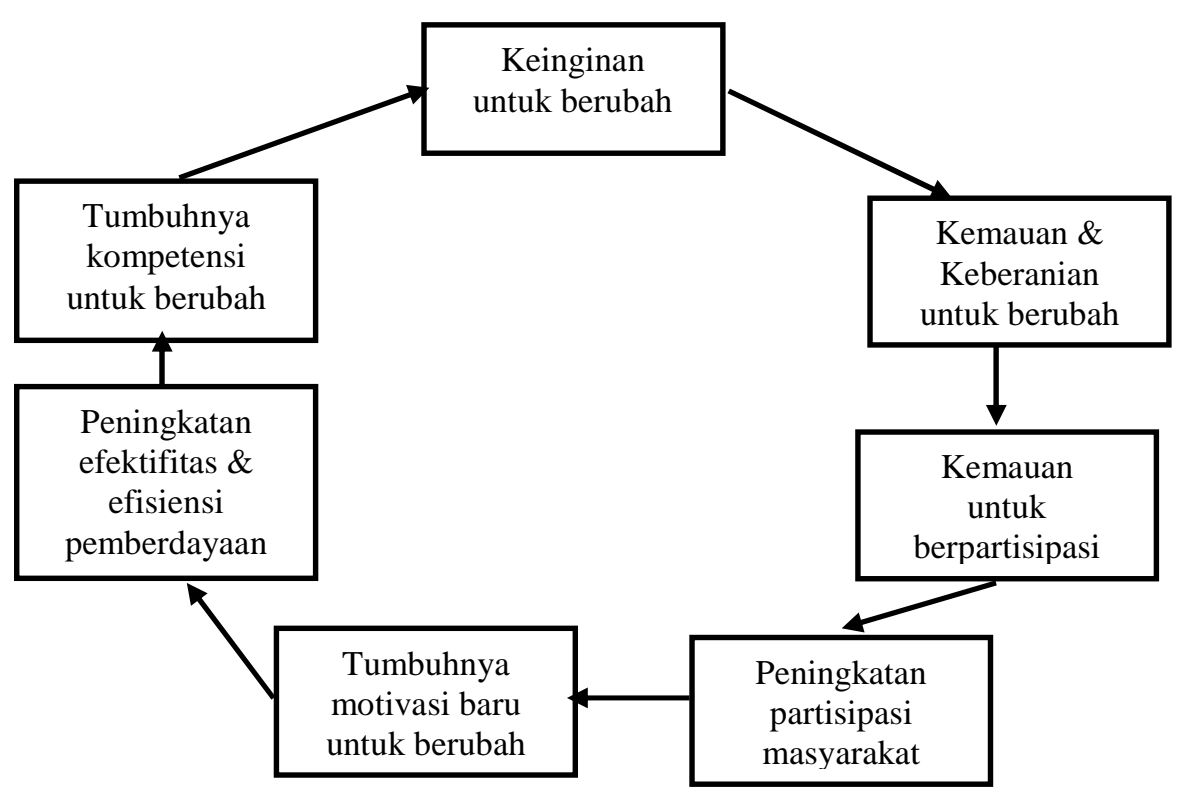

Gambar 2-Siklus Pemberdayaan Masyarakat

Kegiatan pemberdayaan masyarakat melibatkan banyak kepentingan. Untuk itu, penerima manfaat pemberdayaan masyarakat dapat dibedakan menjadi:

1. Pelaku Utama, yang terdiri atas warga masyarakat dan keluarganya.

2. Penentu Kebijakan, terdiri atas aparat pemerintah sebagai perencana, pelaksana, dan pengendali kebijakan pembangunan.

3. Pemangku kepentingan yang lain, yang mendukung kegiatan pembangunan. Termasuk dalam kelompok ini antara lain: pers, budayawan, aktivis LSM, pelaku bisnis, peneliti, dan akademisi.

Tabel 1. Contoh Pembagian Peran Penerima Manfaat Pemberdayaan Masyarakat

\begin{tabular}{|l|c|c|c|c|c|c|}
\hline \multicolumn{1}{|c|}{$\begin{array}{c}\text { Ragam } \\
\text { Kegiatan }\end{array}$} & $\begin{array}{c}\text { Aparat } \\
\text { Pemerintah }\end{array}$ & Peneliti & Akademisi & Swasta & Masyarakat & LSM \\
\hline $\begin{array}{l}\text { Pencentus ide } \\
\text { Pembangunan }\end{array}$ & $\sqrt{ }$ & $\sqrt{ }$ & $\sqrt{ }$ & $\sqrt{ }$ & $\sqrt{ }$ & $\sqrt{ }$ \\
\hline $\begin{array}{l}\text { Pengambil } \\
\text { keputusan }\end{array}$ & $\sqrt{ }$ & & & & & \\
\hline Penyedia Input & $\sqrt{ }$ & & & $\sqrt{ }$ & & \\
\hline Pelaksana Kegiatan & & & & $\sqrt{ }$ & $\sqrt{ }$ & \\
\hline Pemeliharaan Hasil & $\sqrt{ }$ & & & $\sqrt{ }$ & $\sqrt{ }$ & \\
\hline $\begin{array}{l}\text { Pemantauan dan } \\
\text { Evaluasi }\end{array}$ & $\sqrt{ }$ & $\sqrt{ }$ & $\sqrt{ }$ & $\sqrt{ }$ & $\sqrt{ }$ & $\sqrt{ }$ \\
\hline
\end{tabular}

Sumber: Mardikanto, Totok, 2013, hlm: 177 
Destha T. Raharjana ${ }^{1}$, Made Pande Kutanegara ${ }^{2}$-Pemberdayaan Masyarakat di Kawasan Cagar Budaya...

\section{METODE}

Penelitian ini dijalankan dengan pendekatan partisipatif tujuannya untuk mendapatkan gambaran atas kebutuhan program pemberdayaan yang diperlukan masyarakat secara riil. Tahapan pengumpulan data dijalankan dengan cara: (a) Observasi Lapangan. Dalam hal ini, tim melakukan pengamatan berkenaan kondisi potensi dan sumber daya kawasan. Lokasi amatan difokuskan situs cagar budaya Sendang Surocolo dan Goa Jepang. Pada saat melakukan observasi, tim dipandu Rutijo, selaku ketua Kelompok Sadar Wisata (Pokdarwis) Surocolo dan beliau ditugaskan sebagai juru pelihara oleh BPCB DIY. Selama melakukan proses pengamatan tim juga mendapatkan penjelasan terkait dengan kondisi situs yang ada di wilayah Surocolo ini. (b) Wawancara Mendalam. Guna lebih memperdalam temuan saat observasi, satu cara lagi dipergunakan untuk menggali data adalah wawancara. Wawancara mendalam dilakukan dengan Ketua Pokdarwis desa Surocolo. Selain aspek seni dan budaya, data lainnya yang diperoleh terkait dengan cikal bakal pengembangan kawasan ini menjadi desa wisata sekaligus desa budaya. (c) Focus Group Discussion. Tahap ini dijalankan dengan model sarasehan. Pelaksanaan sarasehan dilakukan malam hari dan dihadiri sekitar 30 warga dari dua dusun - Ngreco dan Poyahan. Agenda pertemuan utama para peserta diajak untuk memberikan pandangan atas sumber daya serta peluang pengembangannya juga mendorong warga untuk berpikir tentang kebutuhan pemberdayaan bagi warga setempat yang perlu diberikan oleh pihak terkait.

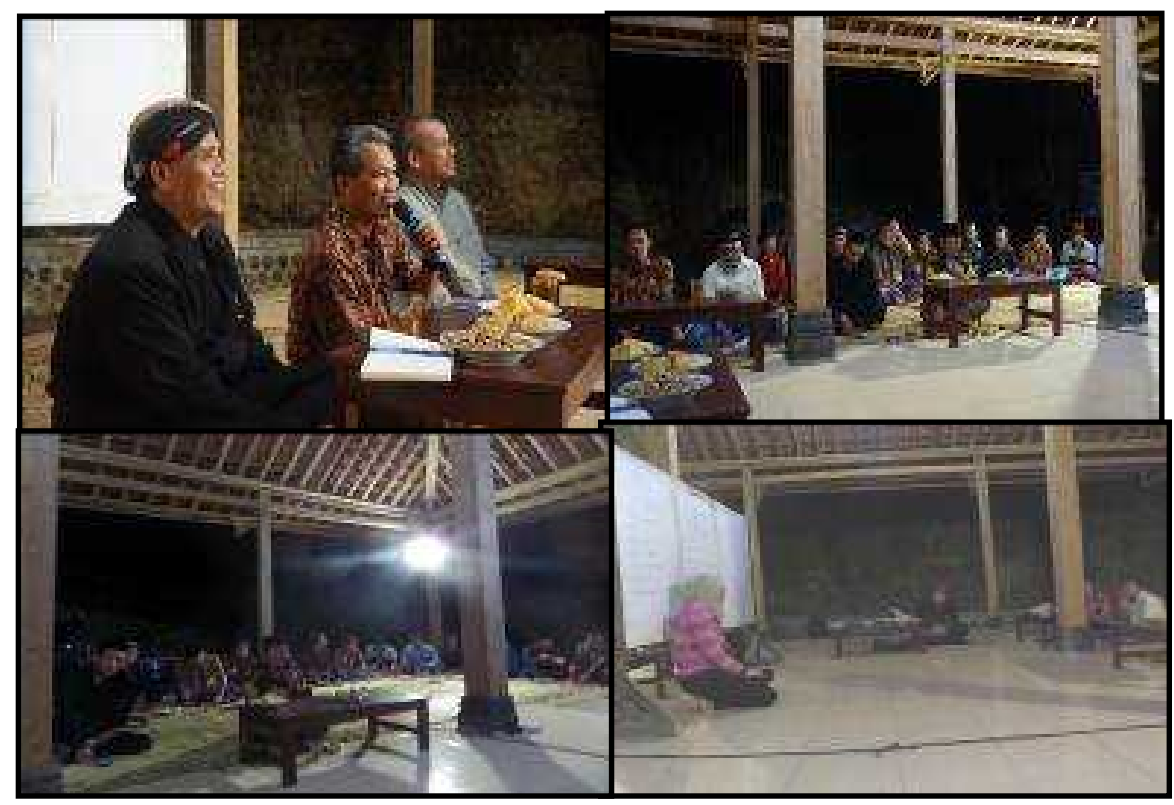

Gambar 3. Pihak BPCB DIY, bapak Taufik (tengah) didampingi tim studi saat memberikan penjelasan diawal pertemuan bersama warga di Pendopo Surocolo Foto: Destha, Puspar 2017. 


\section{HASIL \& PEMBAHASAN}

\section{a. Lokasi Kajian}

Kawasan Surocolo tepatnya Dusun Ngreco dan Poyahan Desa Seloharjo Pundong Bantul Yogyakarta dengan potensinya situs budaya dan tradisi masyarakatnya telah menjadikan Seloharjo ditetapkan menjadi desa wisata sejak tahun 2016. Untuk tahap awal ini, Seloharjo masuk dalam kategori desa wisata embrio dengan potensinya berupa seni budaya dan situs Goa Jepang. Cikal bakal Surocolo itu sendiri, seperti yang masih dipahami masyarakat berasal dari dua kata, yaitu Suro dan Colo. "Suro" artinya berani dan "Colo" adalah memberitahu, sehingga secara harafiah dapat diartikan makna Surocolo dengan berani memberi tahu.

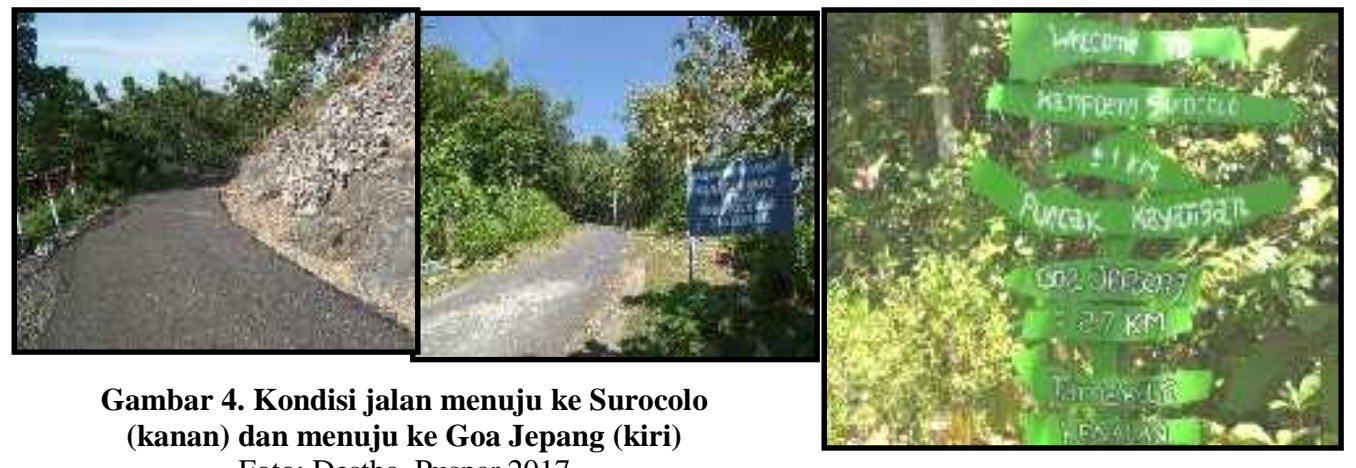
Foto: Destha, Puspar 2017

Untuk menuju ke Surocolo dapat mempergunakan kendaraan bermotor. Lokasi tidak jauh kawasan pantai Parangtritis. Aksesibilitas berupa jalan sudah beraspal dan dalam kondisi baik. Di beberapa bagian jalan menuju lokasi cukup menanjak. Kondisi ini memerlukan kehati-hatian para pengemudi. Hanya saja, dukungan dan fasilitas kendaraan umum menuju ke lokasi wisata ini belum tersedia. Kebanyakan wisatawan yang berkunjung mempergunakan kendaraan pribadi. Bus pariwisata untuk saat ini belum dapat menuju ke kawasan ini.

Bagi wisatawan hendak berkunjung terdapat beberapa alternative bila dari kawasan Imogiri, wisatawan dapat menemukan jembatan Siluk kemudian ke arah barat selatan atau masuk jalan Siluk-Parangtritis terus ikuti jalan tersebut sekitar $8 \mathrm{Km}$, nanti dapat dilihat papan penunjuk arah ke Goa Jepang. Bila wisatawan dari Pundong tinggal menyeberang Jembatan baru Soka, lalu belok kanan terus mengikuti jalan SilukParangtritis, sekitar $1 \mathrm{~km}$ maka telah sampai jalan masuk ke arah Goa Jepang. Bila dari Jalan Parangtritis maka setelah jembatan Kretek atau sebelah utara pintu TPR Parangtritis, belok kiri, masuk ke jalan Siluk-Parangtritis, sekitar 2 Km, maka akan sampai ke jalan masuk ke Goa Jepang.

\section{b. Kondisi Geografis dan Demografis}

Desa Seloharjo termasuk wilayah Kecamatan Pundong Kabupaten Bantul Yogyakarta. Lokasinya berbatasan langsung dengan wilayah Kabupaten Gunung Kidul di bagian Selatan, di sebelah timur berbatasan dengan Desa Selopamioro, sebelah Barat berbatasan dengan Desa Parangtritis, dan di sebelah Utara berbatasan dengan Desa Panjangrejo dan Desa Srihardono. Luas desanya $11,10 \mathrm{~km}^{2}$. Desa ini dapat dicapai 
dengan menggunakan kendaraan pribadi dengan jarak 27 kilometer dari pusat kota. Akses menuju Desa Seloharjo sudah berupa jalan aspal meskipun tidak terlalu lebar, namun masih memungkinkan untuk mobil atau bis ukuran kecil untuk melintas. Desa ini memiliki 16 padukuhan, yaitu: Dukuh, Nambangan, Pentung, Darmojurang, Bobok Tempel, Geger, Soka, Karangasem, Ngentak, Biro, Kalipakem, Blali, Ngreco, Poyahan, Jelapan, dan Kalinampu. Kantor desanya terletak di dukuh Soka. Dari 16 pedukuhan terbagi dalam 73 Rukun Tetangga (RT). Dari segi demografi jumlah penduduk Desa Seloharjo adalah 14.183 jiwa (Sumber: Monografi Desa Semester II/2016), meliputi 6.969 orang berjenis kelamin laki-laki dan sebanyak 7.134 berjenis kelamin perempuan. Rincian jumlah penduduk berdasarkan kelompok usia dapat dilihat sebagai berikut.

Tabel 2. Jumlah penduduk Desa Seloharjo berdasarkan kelompok umur

\begin{tabular}{|c|c|}
\hline Kelompok Umur & Jumlah \\
\hline $0-15$ & 3.116 \\
$15-65$ & 7.982 \\
$65+$ & 3.085 \\
\hline Jumlah & 14.183 \\
\hline
\end{tabular}

Sumber: diolah dari Buku Monografi Desa Semester II/ 2016

Kondisi lingkungan desanya mendukung untuk kegiatan persawahan dan peternakan membuat sebagian besar warga berprofesi sebagai petani, buruh tani, dan peternak. Selain itu, banyak pula warga yang bekerja di bidang jasa dan perdagangan. Terdapat sekitar 1.384 petani. Ada pula yang menjadi karyawan, buruh tani, peternak, dan lainnya. Tingkat pendidikan warga rata-rata adalah lulusan SMP. Pada umumnya masyarakat yang telah lulus sekolah menengah pertama ataupun atas memutuskan untuk pergi merantau keluar kota dan bekerja sebagai buruh pabrik.

Tabel 3. Tingkat Pendidikan Penduduk Desa Seloharjo

\begin{tabular}{|l|c|}
\hline Pendidikan Terakhir & \multicolumn{2}{|c|}{ Jumlah } \\
\hline Taman Kanak-kanak & \multicolumn{2}{|c|}{311} \\
\hline SD/sederajat & 457 \\
\hline SMP/sederajat & \multicolumn{2}{|c|}{735} \\
\hline SMA/sederajat & \multicolumn{2}{|c|}{813} \\
\hline Akademi (D1-D3) & \multicolumn{2}{|c|}{46} \\
\hline Sarjana (S1) & \multicolumn{2}{|c|}{42} \\
\hline Pascasarjana & S2: 11 \\
\hline Pesantren & \multicolumn{2}{|c|}{2} \\
\hline Kursus keterampilan & \multicolumn{2}{|c|}{11} \\
\hline
\end{tabular}

Sumber: diolah dari Buku Monografi Desa Semester II/2016 
c. Keragaman Potensi Budaya di Kawasan Surocolo

Daya tarik budaya dalam wujud material yang dapat ditemukan di Desa Seloharjo, antara lain Goa Surocolo. Dulunya goa ini sebagai tempat petilasan pertapaan Sunan Mas atau yang dikenal sebagai Sunan Mangkurat III. Sunan Mas merupakan keturunan Amangkurat II. Beberapa versi cerita yang muncul di masyarakat terkait Goa Surocolo dulunya dipergunakan oleh Sunan Mas untuk melakukan persembunyian. Mitos atau kisah sejarah situs yang menjadi cagar budaya membuat Seloharjo potensi guna dikembangkan lebih jauh.

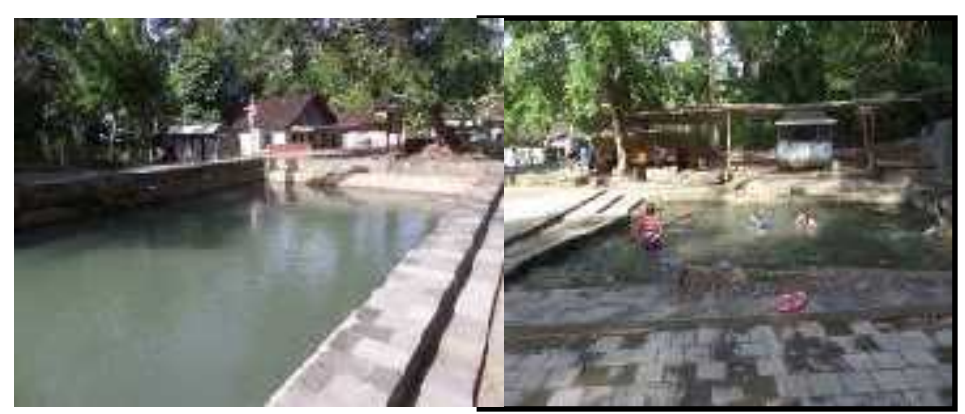

Gambar 5. Dikala hari kerja tidak banyak pengunjung, hanya orang sekitar objek khususnya anak-anak yang memanfaatkan untuk bermain air di Sendang Surocolo. Foto: Destha, Puspar UGM, 2017

Di sekitar goa terdapat kolam atau sendang, satu buah sendang ukuran besar dan dua buah sendang berukuran lebih kecil. Di dekat sendang yang berukuran kecil, terdapat dua buah pohon besar yang telah berusia ratusan tahun, yaitu Pohon Randu Alas dan Kepuh. Kedua pohon tersebut dipercaya sebagai perlambang kejadian yang berhubungan dengan petinggi negara. Pada sendang yang berukuran kecil, yang juga disebut Sendang Lanang dan Sendang Wadon, terdapat arca zaman Hindu, yaitu Arca Mahakala dan Arca Jaladwara. Saat ini, Sendang Lanang dan Sendang Wadon sering digunakan anak-anak untuk bermain air.

Objek budaya lainnya adalah goa Sunan Mas. Goa ini bentuknya berupa cerukan di tebing batu yang berada di dukuh Ngreco. Goa ini merupakan tempat pertapaan dan persembunyian Sunan Mas atau Sunan Amangkurat III yang dibuat pada zaman Kerajaan Mataram (Dinas Kebudayaan dan Pariwisata Kabupaten Bantul, 2012). Kisahnya, ketika pada pengikut Sunan Mas sedang membuat Goa, Ki Joko Umar dan ibunya, Nyi Glenggang Jati atau Nyi Rondho, datang menghampiri. Ki Joko Umar yang saat itu masih anak-anak mengatakan bahwa dia mempunyai cara yang lebih cepat untuk membuat Goa. Akhirnya, dengan menggunakan tempurung kelapa, Ki Joko Umar mampu membuat Goa yang digunakan Sunan Mas untuk berlindung (Manuskrip). Di sekitar Goa Sunan Mas juga terdapat Goa Sigolo-golo atau Goa siluman yang pernah digunakan sebagai tempat persembunyian Pangeran Diponegoro. 
Destha T. Raharjana ${ }^{1}$, Made Pande Kutanegara ${ }^{2}$-Pemberdayaan Masyarakat di Kawasan Cagar Budaya...
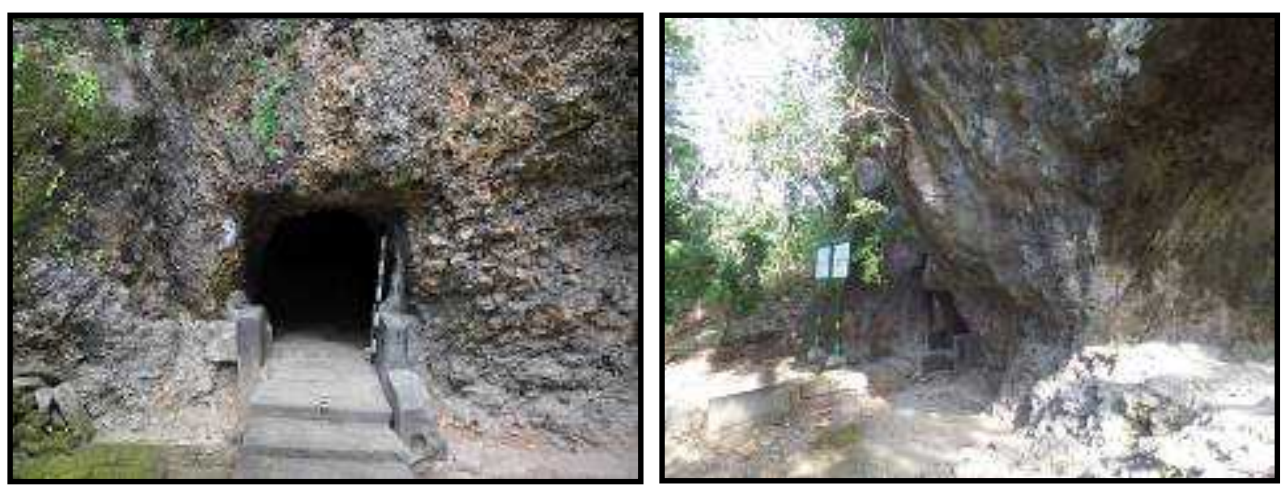

Gambar 6. Goa Sunan Mas

Foto: Destha, Puspar UGM, 2017

Selanjutnya adalah Goa Jepang. Kawasan goa ini berada di wilayah Kabupaten Bantul dan Kabupaten Gunungkidul. Sesuai Undang-Undang Nomor 11 Tahun 2010 tentang Cagar Budaya, Situs Cagar Budaya atau Kawasan Cagar budaya yang berada di 2 (dua) kabupaten/kota atau lebih ditetapkan sebagai kawasan cagar budaya provinsi DIY.

Goa Jepang yang terdapat di Pundong ini merupakan peninggalan Perang Dunia II. Terdapat 18 Goa yang tersebar di area seluas 25 hektar. Secara administratif, dari 18 Goa Jepang yang ada, 16 Goa masuk ke dalam wilayah administratif kecamatan Pundong, Bantul (Goa nomor 2 hingga Goa nomor 17) dan 2 lainnya masuk ke dalam wilayah Gunungkidul (Goa nomor 1 dan nomor 18) (zonasi jepang). Goa-Goa tersebut memiliki beragam ukuran dan bentuk yang disesuaikan dengan peruntukannya. Goa Jepang tersebut telah masuk dalam Zona I atau Zona Inti yang ditetapkan oleh BPCB Yogyakarta. Artinya, Goa-Goa tersebut merupakan situs budaya yang dilindungi secara ketat, sehingga segala bentuk perubahan yang terjadi harus dilakukan secara terbatas dan terencana.

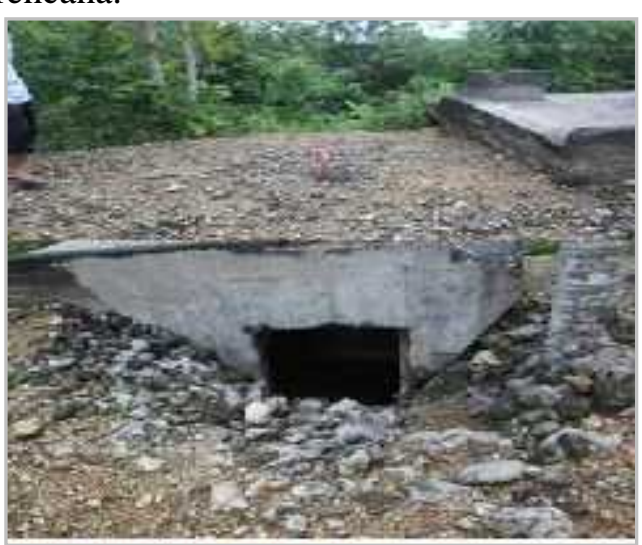

Goa 5 Dengan satu lubang pengintaian

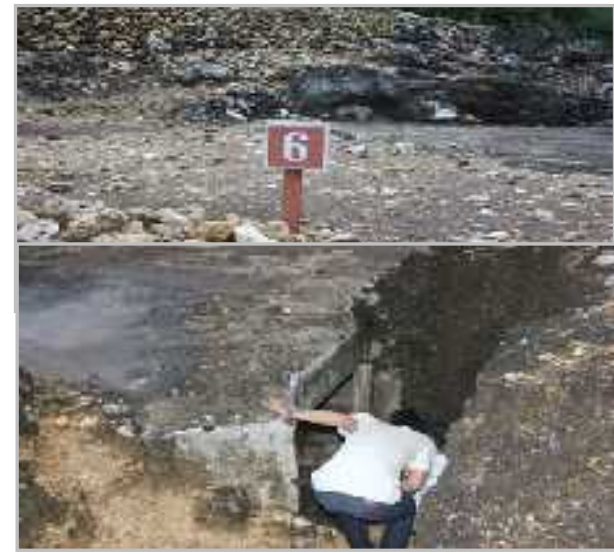

Goa 6 Satu Pintu Tempat Pertemuan

Gambar 7. Kondisi Goa Jepang No 5 dan 6

Foto: BPCB DIY 2017 
Wujud atraksi budaya non-bendawi dan rutin berjalan setahun sekali adalah Merti Bumi, masyarakat menyebutnya Nyadranan. Pada acara tersebut, warga mempertunjukkan berbagai pertunjukkan kesenian dan mengarak gunungan yang berisi hasil bumi. Upacara ini merupakan tradisi turun temurun yang bertujuan untuk memohon turunnya hujan kepada Yang Maha Kuasa agar warga dapat memulai musim tanam baru. Tradisi ini dilakukan pada Mangsa Kapat, yaitu sekitar bulan September hingga Oktober dan terbuka bagi wisatawan untuk dapat menyaksikan tradisi ini.

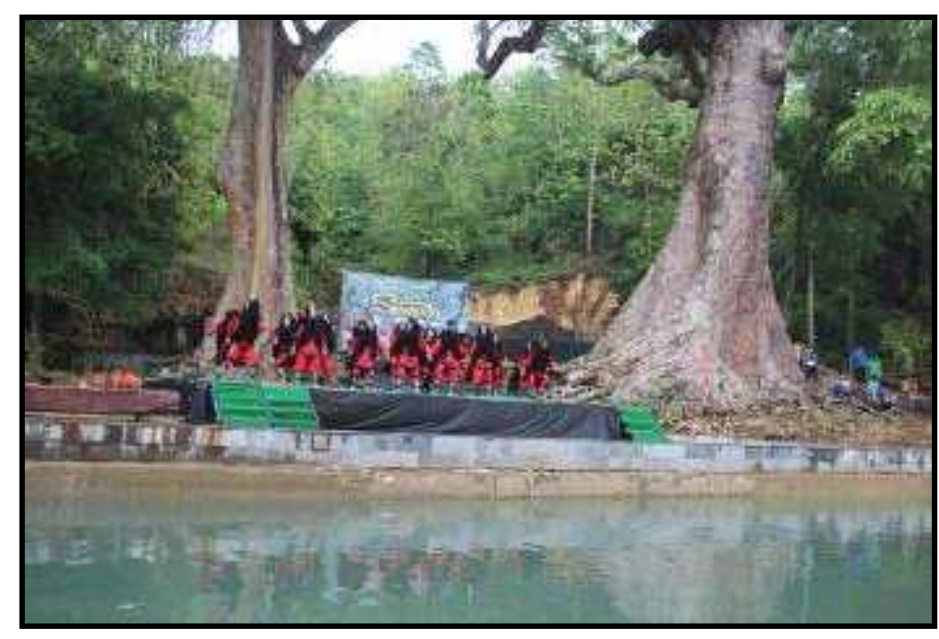

Gambar 8. Tarian Rampak Buto di depan Sendang Surocolo Foto: BPCB DIY 2017

Nyadran di Surocolo tidak dilakukan pada bulan Sya'ban namun dilakukan pada puncak musim kemarau di mangsa kapat. Selain itu, yang membedakan tradisi Nyadran lainnya, adalah serangkaian ritual yang dilakukan. Pada hari pertama, warga desa melakukan bersih desa dan kemudian pada malam hari dilakukan tahlilan dan malam tirakat. Hari berikutnya dilakukan segala persiapan fisik, seperti membuat gunungan dan membuat panggung. Pada hari ketiga, yaitu hari Rabu, warga desa akan menyembelih seekor kambing dan seekor ayam di Sendang Putri. Setelah itu, daging kambing dan ayam akan dimasak krawon oleh ibu-ibu setempat. Krawon adalah olahan daging kambing yang cara memasakanya adalah dengan mencincang dan mencampurnya dengan parutan kelapa. Masakan ini memiliki makna manunggaling rakyat kalih pemimpin atau kebersatuan antara rakyat dan pemimpinnya.

Pada puncak acara Merti Bumi, warga desa akan mengarak gunungan yang berisi hasil bumi yang dikawal oleh bregodo yang berjumlah 60 orang pemuda pemudi. Para pemuda mengawal gunungan sementara para pemudi akan membawa tambir yang berisi krawon yang telah dibungkus untuk kemudian dibagikan kepada warga dan tamu-tamu undangan. Tradisi Merti Bumi mulanya hanya merupakan tradisi tahunan yang dilakukan warga Surocolo, namun setelah terbentuk Pokdawis, maka tradisi Merti Bumi dikreasikan sedemikian rupa agar memiliki daya tarik untuk menarik minat wisatawan. 
d. Pemberdayaan Masyarakat di Kawasan Cagar Budaya

Berangkat dari pandangan, masyarakat adalah pemilik sah warisan budaya (Cleere, 1989), maka masyarakat lokal yang bermukim di sekitar situs penting diposisikan sebagai salah satu sumber pertimbangan utama dalam kegiatan yang menyangkut persoalan warisan budaya. Model alternatif yang dikembangkan masyarakat diberi peran yang lebih besar untuk ikut serta menentukan pengelolaan sumber daya arkeologi di daerahnya. Posisi pemerintah tidak lagi ditempatkan sebagai penentu kebijakan tunggal, melainkan lebih banyak berperan sebagai fasilitator. Pemberdayaan sebagai proses mengembangkan, memandirikan, menswadayakan, memperkuat posisi tawar menawar masyarakat lapisan bawah terhadap kekuatan-kekuatan penekan di segala bidang dan sektor kehidupan (Sutoro Eko, 2002).

Pendekatan yang berorientasi masyarakat dalam implementasinya diwujudkan melalui pemberdayaan masyarakat di sekitar situs. Pendekatan ini mempunyai keuntungan bagi kedua belah pihak, antara pihak pengelola warisan budaya dengan pihak masyarakat di sekitar situs. Pihak pengelola, yakni pemerintah dalam upaya pelestarian memperoleh dukungan dari masyarakat, karena mereka membutuhkan peran dari warisan tersebut. Sebaliknya, masyarakat juga mendapatkan keuntungan, baik moril maupun materiil karena warisan budaya dapat memberikan kontribusi konkrit yang dapat meningkatkan taraf perekonomian (Prasodjo 2004). Pendekatan berorientasi pada keterlibatan masyarakat yang diimplementasikan dalam bentuk pemberdayaan, merupakan langkah resolusi yang diperkirakan mampu meredam atau bahkan menghilangkan konflik pemanfaatan warisan budaya (Sulistyanto, 2008).

Pada tahap awal penyusunan rancangan program pemberdayaan adalah melakukan mapping bersama masyarakat untuk mengidentifikasi potensi dan kendala yang dirasakan. Dari kegiatan rembug bersama warga, tim melakukan identifikasi potensi di kawasan Surocolo dan sekitarnya. Secara ringkas hasil identifikasi memperlihatkan adanya daya tarik alam serta didukung dengan daya tarik budaya, baik yang bersifat tangible ataupun intangible, simak di tabel 5, berikut.

Tabel 5. Identifikasi Potensi Budaya Kawasan Surocolo

\begin{tabular}{|c|c|c|}
\hline Potensi & Jenis Potensi & Kondisi Aktual Potensi \\
\hline $\begin{array}{c}\text { Budaya } \\
\text { (Tangible) }\end{array}$ & Goa Jepang & $\begin{array}{l}\text { - } \quad \text { Akses jalan menuju ke objek relative menanjak dan sempit. } \\
\text { - } \quad \text { Belum ada rambu-rambu dan pagar pengaman. } \\
\text { - } \quad \text { Belum tersedia lokasi parkir di sekitar objek. } \\
\text { - } \quad \text { Belum tersedia MCK dan air bersih di sekitar objek. } \\
\text { - } \quad \text { Kondisi alam, tiupan angin yang kencang di musim tertentu. } \\
\text { - } \quad \text { Kudah ada sarana gazebo dan wahana untuk swafoto. } \\
\text { - } \quad \text { Belum dilengkapi dengan papan interpretasi objek/situs. } \\
\text { - } \quad \text { Perlunya petugas jaga yang rutin mengawasi perilaku negative } \\
\quad \text { wisatawan guna mencegah tindakan vandalism, antisipasi } \\
\text { terjadinya perbuatan mesum, ataupun mencegah agar objek tidak } \\
\text { kotor objek dan lainnya. }\end{array}$ \\
\hline
\end{tabular}




\begin{tabular}{|c|c|c|}
\hline & $\begin{array}{l}\text { Sendang } \\
\text { Surocolo }\end{array}$ & 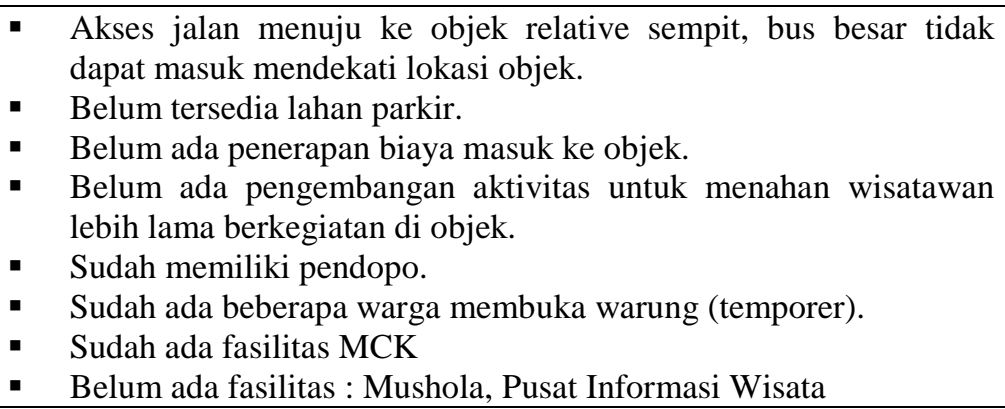 \\
\hline Alam & $\begin{array}{l}\text { Puncak } \\
\text { Khayangan }\end{array}$ & $\begin{array}{l}\text { - Memiliki view ke arah pantai Parangtritis, pantai Depok, pantai } \\
\text { Parangkusumo, gumuk pasir, dan museum Geospasial. } \\
\text { - } \quad \text { Berada satu kawasan dengan Goa Jepang. } \\
\text { - } \text { Memiliki ruang untuk dipergunakan camping. } \\
\text { - } \text { Akses jalan untuk bus besar tidak dapat masuk. } \\
\text { - Belum ada fasilitas penunjang/amenitas. }\end{array}$ \\
\hline \multirow[t]{2}{*}{$\begin{array}{c}\text { Budaya } \\
\text { (Intagible) }\end{array}$} & $\begin{array}{l}\text { Seni } \\
\text { Tradisi }\end{array}$ & $\begin{array}{l}\text { - } \text { Ada kelompok budaya (Pokdaya) Surocolo } \\
\text { - } \quad \text { Adanya event budaya regular: tradisi Nyadran, setiap bulan Rajab } \\
\text { - Memiliki sanggar budaya: kethoprak, karawitan } \\
\text { - Memiliki pasukan Bergodo }\end{array}$ \\
\hline & Kuliner & $\begin{array}{l}\text { - } \quad \text { Minuman (wedang) rempah "Wedang Ereng-Ereng" } \\
\text { - } \quad \text { Makanan sego sangit sambel kopi } \\
\text { - } \quad \text { MieDhes (mie pedas) khas Bantul }\end{array}$ \\
\hline
\end{tabular}

Sumber: diolah dari rembug warga, 2017

Dari kegiatan rembug bersama warga Seloharjo, tampak terbersit motivasi serta semangat guna mendorong penguatan sumber daya yang dimiliki untuk lebih mampu didayagunakan. Keberadaan Sendang Surocolo, Goa Jepang yang keduanya termasuk situs atau cagar budaya merupakan satu modal pendukung yang sudah dimiliki selain juga tentunya semangat masyarakat untuk mengemas potensi menjadi daya tarik. Hal inilah yang selanjutnya mendorong warga Surocolo khususnya mengupayakan segenap potensi yang dimiliki dan saat ini sudah dikembangkan.

Sektor pariwisata dinilai strategis mampu memicu peluang "baru" bagi pemberdayaan masyarakat Seloharjo, khususnya kalangan generasi muda agar mereka tidak meninggalkan desa untuk bekerja ke daerah lain. Dari pertemuan bersama warga juga dapat diperoleh gambaran arah pengembangan dari potensi yang tersedia dan kemungkinan pengembangan ke depan. Mulai dari potensi seni budaya tradisional yang masih dijalani warga juga kegiatan ekonomi kreatif yang sehari-hari dijadikan sebagai sumber penghidupan.

Tabel 6. Peluang Pengembangan Potensi Desa Seloharjo

\begin{tabular}{|l|l|}
\hline \multicolumn{1}{|c|}{$\begin{array}{c}\text { Potensial } \\
\text { Atraksi }\end{array}$} & \multicolumn{1}{c|}{ Arahan Pengembangan } \\
\hline Goa Jepang & - $\begin{array}{l}\text { Penatan sarana pendukung wisata, seperti warung makan, MCK, lahan } \\
\text { parkir, pintu gerbang dan lainnya sesuai dengan zona diijinkan pihak }\end{array}$ \\
& - $\begin{array}{l}\text { BPCB DIY. } \\
\text { Penambahan papan interpretasi atas situs yang ada guna memudahkan } \\
\text { informasi diterima/dibaca oleh wisatawan. }\end{array}$ \\
& - $\begin{array}{l}\text { Pengembangan sarana keselamatan bagi wisatawan, baik untuk sarana } \\
\text { jalan menuju ke objek (mis: kaca cembung) ataupun pada sarana atraksi }\end{array}$ \\
\hline
\end{tabular}


Destha T. Raharjana ${ }^{1}$, Made Pande Kutanegara²-Pemberdayaan Masyarakat di Kawasan Cagar Budaya...

\begin{tabular}{|c|c|}
\hline & $\begin{array}{l}\text { wisatanya. } \\
\text { - } \quad \text { Pengembangan jaringan air bersih, jaringan listrik, pembuangan sampah. } \\
\text { - Penambahan gazebo, pos kesehatan, pos informasi di sekitar Goa Jepang. }\end{array}$ \\
\hline $\begin{array}{l}\text { Sendang } \\
\text { Surocolo }\end{array}$ & 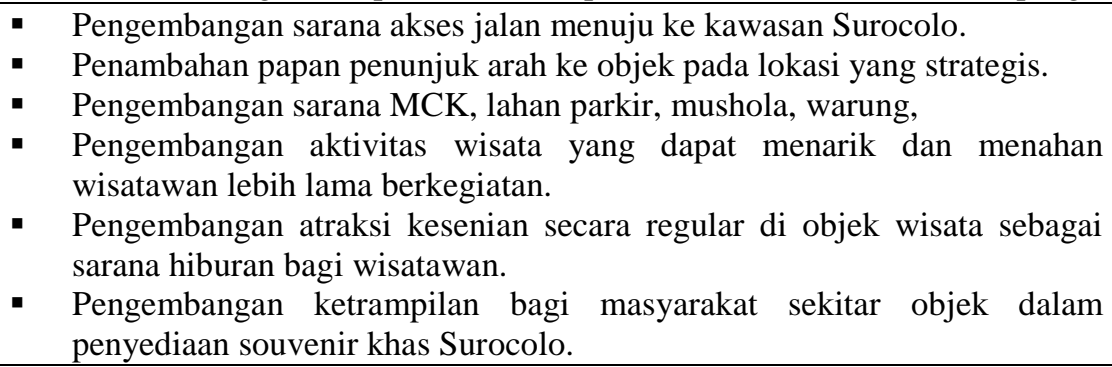 \\
\hline $\begin{array}{l}\text { Puncak } \\
\text { Khayangan }\end{array}$ & $\begin{array}{l}\text { - Pengembangan kawasan camping ground di Puncak Khayangan. } \\
\text { - Pengembangan infrastruktur untuk mendukung pemanfaatan sebagai } \\
\text { camping ground. }\end{array}$ \\
\hline $\begin{array}{l}\text { Seni } \\
\text { Tradisi / }\end{array}$ & $\begin{array}{l}\text { - Pengembangan seni pertunjukan dengan setting cerita terkait dengan } \\
\text { - Situs/Sendang Surocolo. (semacam fragmen). } \\
\text { Pengemasan tradisi Nyadran agar lebih menarik minat wisatawan untuk } \\
\text { melihatnya. }\end{array}$ \\
\hline Ekonomi Kreatif & $\begin{array}{l}\text { - Pengembangan souvenir, misalnya batik, ukir kayu, dan sebagainya } \\
\text { dengan tetap menonjolkan karakter Surocolo. }\end{array}$ \\
\hline Kuliner & $\begin{array}{l}\text { - Peningkatan ketrampilan dibidang memasak : pembuatan makanan atau } \\
\text { minuman khas Surocolo. } \\
\text { - Pengembangan cita rasa olahan dan penyajian agar sesuai dengan taste } \\
\text { wisatawan. }\end{array}$ \\
\hline
\end{tabular}

Sumber: diolah dari hasil rembug warga, 2017

Sesuai dengan tujuan dilaksanakan kajian ini, selanjutnya diperoleh pemetaan kebutuhan program pemberdayaan masyarakat desa Seloharjo, umumnya dan khususnya bagi dua dusun yang memiliki cagar budaya. Berikut dapat dilihat rancangan program pemberdayaan masyarakat yang dibutuhkan masyarakat Seloharjo.

Tabel 7. Rancangan Pemberdayaan Masyarakat Desa Seloharjo (Kawasan Surocolo, Pundong)

\begin{tabular}{|c|c|c|c|}
\hline BIDANG & SASARAN & DETAIL JENIS PEMBERDAYAAN & $\begin{array}{c}\text { DUKUNGAN } \\
\text { PIHAK } \\
\text { TERKAIT }\end{array}$ \\
\hline $\begin{array}{l}\text { PENGEMBANGAN } \\
\text { PARIWISATA }\end{array}$ & $\begin{array}{l}\text { Masyarakat, } \\
\text { perangkat desa, } \\
\text { pelaku usaha, } \\
\text { Pokdarwis, } \\
\text { Pokdaya }\end{array}$ & $\begin{array}{ll}\text { 1. } & \text { Bimbingan teknis di bidang: } \\
\text { - } & \text { Peningkatan motivasi diri bagi } \\
& \text { warga lokal } \\
\text { - } & \text { Sapta Pesona dan Sadar Wisata } \\
\text { - } & \text { Pengemasan Paket Wisata } \\
\text { - } & \text { Pengembangan Pemasaran } \\
\text { - } \quad \text { Manajemen kelembagaan } \\
\text { 2. Pokdarwis } \\
\text { Bimbingan teknis bagi para Pemandu } \\
\text { 3. Phusus dibidang Cagar Budaya } \\
\text { Pelatihan Bahasa Inggris untuk } \\
\text { Pemandu Lokal }\end{array}$ & $\begin{array}{l}\text { Dinas Pariwisata } \\
\text { Pusat Studi } \\
\text { Pariwisata UGM } \\
\text { BPCB DIY } \\
\text { HPI DIY }\end{array}$ \\
\hline
\end{tabular}


Jurnal Tata Kelola Seni-Vol. 5 No. 1 Juni 2019

p-ISSN 2442-9589, e-ISSN 2614-7009

\begin{tabular}{|c|c|c|c|}
\hline $\begin{array}{l}\text { PENGEMBANGAN } \\
\text { EKONOMI } \\
\text { KREATIF }\end{array}$ & $\begin{array}{l}\text { Kelompok } \\
\text { Usaha Bersama } \\
\text { (KUBE) } \\
\text { Masyarakat } \\
\text { Desa }\end{array}$ & $\begin{array}{ll}\text { 1. } & \text { Pelatihan Souvenir (bahan kayu) } \\
\text { 2. } & \text { Pelatihan Souvenir (bahan kain) } \\
\text { 3. } & \text { Pelatihan Sablon } \\
\text { 4. } & \text { Pelatihan Kuliner (produksi dan } \\
& \text { pengemasan produk lokal) }\end{array}$ & $\begin{array}{l}\text { Pelaku kerajinan } \\
\text { terkait } \\
\text { Pelaku / Praktisi } \\
\text { Tata Boga }\end{array}$ \\
\hline $\begin{array}{l}\text { PENGEMBANGAN } \\
\text { SENI BUDAYA }\end{array}$ & $\begin{array}{l}\text { Pelaku Kesenian } \\
\text { Pelaku Wisata }\end{array}$ & $\begin{array}{l}\text { 1. Pengembangan Kelompok Kesenian } \\
\text { 2. Pengembangan tarian untuk fragmen } \\
\text { Surocolo } \\
\text { 3. Bimbingan teknis Manajemen Event }\end{array}$ & $\begin{array}{l}\text { Dinas } \\
\text { Kebudayaan } \\
\text { ISI }\end{array}$ \\
\hline KEWIRAUSAHAAN & $\begin{array}{l}\text { Pelaku Wisata } \\
\text { Pelaku Usaha } \\
\text { Pokdarwis }\end{array}$ & $\begin{array}{l}\text { 1. Pelatihan Kewirausahaan } \\
\text { 2. Pelatihan Pelayanan Prima (warung, } \\
\text { rumah makan, homestay, area parkir, } \\
\text { dan pemandu wisata) }\end{array}$ & $\begin{array}{l}\text { Praktisi } \\
\text { Wirausaha }\end{array}$ \\
\hline
\end{tabular}

Sumber: diolah dari rembug warga, 2017

\section{KESIMPULAN}

Meminjam kutipan Dickens dan Hill (Tanudirdjo, 2003) "Kita harus melestarikan sumber daya itu jika kita ingin mengambil manfaat darinya, kita harus mempelajarinya jika ingin memahami manfaat yang dapat kita peroleh dan kita harus menerjemahkan pengetahuan yang kita peroleh untuk masyarakat. Jadi, dari masyarakatlah proses pelestarian ini berawal dan kepada merekalah semua harus diserahkan", dalam rangka pengelolaan cagar budaya, perlunya dipahami bahwa menempatkan masyarakat sekitar situs dalam kerangka penyusunan perencanaan adalah keharusan.

Dalam konteks pemberdayaan masyarakat di kawasan Surocolo, kajian ini mampu menghasilkan (i) identifikasi potensi dan kondisi aktual yang ditemukan di kawasan. Potensi yang dapat diidentifikasi adalah potensi budaya bendawi yakni Goa Jepan, Sendang Surocolo, Puncak Kahyangan, serta ada pula yang non-bendawi yakni seni tradisi dan kuliner khas yang berpeluang untuk dikembangkan, (ii) identifkasi peluang pengembangan dari sumber daya yang ada di kawasan Surocolo, dan (iii) menyusun rancangan program pemberdayaan masyarakat sekitar cagar budaya. Beberapa rancangan program pemberdayaan dihasilkan dipastikan melibatkan berbagai pihak (akademisi, praktisi, dan budayawan), khususnya dalam pemberdayaan masyarakat dibidang pengembangan pariwisata, pengembangan ekonomi kreatif, pengembangan seni budaya dan peningkatan kapasitas masyarakat dibidang kewirausahaan.

\section{Ucapan Terima kasih:}

Disampaikan terima kasih kepada Balai Pelestarian Cagar Budaya (BPCB) DIY yang telah bekerjasama dengan Pusat Studi Pariwisata UGM, tahun 2017 dalam menyusun Kajian Potensi Pemberdayaan Masyarakat Pundong, Kabupaten Bantul DIY.

\section{KEPUSTAKAAN}

Anonim, 2012. Dinas Kebudayaan dan Pariwisata Kabupaten Bantul. 2012. Warisan Budaya dan Cagar Budaya. Dinas Kebudayaan dan Pariwisata Kabupaten Bantul: Bantul

Anonim. tt. Laporan Ekskavasi Gua Jepang - Zonasi Jepang. BPCB DIY. 
Destha T. Raharjana', Made Pande Kutanegara ${ }^{2}$-Pemberdayaan Masyarakat di Kawasan Cagar Budaya...

Anonim. 2016. Buku Monografi Desa Semester II Tahun 2016. Desa Seloharjo, Kecamatan Pundong, Kabupaten Bantul.

Anonim. tt. Profil Desa Wisata Desal Seloharjo, Kecamatan Pundong, Kabupaten Bantul, Daerah Istimewa Yogyakarta.

Anonim. 2016. "Keputusan Bupati Bantul Nomor 240 tahun 2016 Tentang Penggolongan Klasifikasi Desa Wisata di Kabupaten Bantul".

Anonim. 2013. Dokumen "Keputusan Lurah Desa Seloharjo, Kecamatan Pundong, Kabupaten Bantul Nomor 07 tahun 2013 Tentang Pengukuhan Kelimpik Sadar Wisata (Pokdarwis) Kampung Surocolo Dusun Poyahan dan Dusun Ngreco Desa Seloharjo, Kecamatan Pundong, Kabupaten Bantul”.

Kusnadi. 2015. Pemberdayaan Perempuan Pesisir: Pengembangan Sosial Ekonomi Masyarakat Pesisir melalui Budidaya Rumput Laut. Graha Ilmu: Yogyakarta.

Mardikanto, Totok, Poerwoko Soebiato. 2013. Pemberdayaan Masyarakat dalam Perspektif Kebijakan Publik. Alfabeta: Bandung.

Sulstyanto, Bambang. 2003. Balung Buto: Warisan Budaya Dunia dalam Perspektif Masyarakat Sangiran. Kunci Ilmu: Yogyakarta.

Suharto, Edi. 2005. Membangun Masyarakat Memberdayakan Rakyat. PT Refika Aditama: Bandung.

Santosa, Imam. 2014. Pengembangan Masyarakat berbasis Sumber Daya Lokal. Pustaka Pelajar: Yogyakarta.

Tanudirdjo, Daud. 1998. "Cultural Resource Management as Conflict Management", Artefak Magazine No. 19, hlm: 14-18.

Webtografi:

http://kec-pundong.bantulkab.go.id/desa/seloharjo https://bantulkab.bps.go.id/ipds@ 3402/pdf_publikasi/Kecamatan-Pundong-Dalam-

Angka-2016.pdf

http://desaseloharjo.blogspot.co.id/2014/10/kampoeng-wisata-surocolo-goa-jepang.html 